\title{
Pharmacological Properties of CDBT in Hypoxia-induced Neuronal Cell Injury and Their Underlying Mechanisms
}

\author{
Sang-kyu Park, Eun-sun Jung, Ji-yoon Cha, Hyun-kyoung Cho, Ho-ryong Yoo, Yoon-sik Kim, In-chan Seol \\ Dept. of Internal Korean Medicine, Dunsan Korean Medicine Hospital of Dae-Jeon University
}

\section{Pharmacological Properties of CDBT in Hypoxia-induced Neuronal Cell Injury and Their Underlying Mechanisms}

\author{
Sang-kyu Park, Eun-sun Jung, Ji-yoon Cha, Hyun-kyoung Cho, Ho-ryong Yoo, Yoon-sik Kim, In-chan Seol \\ Dept. of Internal Korean Medicine, Dunsan Korean Medicine Hospital of Dae-Jeon University
}

\begin{abstract}
Objectives: This study aimed to reveal the pharmacological properties of the newly prescribed herbal mixture, Chenmadansamgamibokhap-tang (CDBT), against hypoxia-induced neuronal cell injury (especially mouse hippocampal neuronal cell line, HT-22 cells) and their corresponding mechanisms.

Methods: A cell-based in vitro experiment, in which a hypoxia condition induced neuronal cell death, was performed. Various concentrations of the CDBT were pre-treated to the HT-22 cells for $4 \mathrm{~h}$ before $18 \mathrm{~h}$ in the hypoxia chamber. The glial cell BV-2 cells were stimulated with IFNr and LSP to produce inflammatory cytokines and reactive oxygen species. When the neuronal HT-22 cells were treated with this culture solution, the drug efficacy against neuronal cell death was examined.

Results: CDBT showed cytotoxicity in the normal condition of HT-22 cells at a dose of $125 \mu \mathrm{g} / \mathrm{mL}$ and showed a protective effect against hypoxia-induced neuronal cell death at a dose of $31.3 \mu \mathrm{g} / \mathrm{mL}$. CDBT prevented hypoxia-induced neuronal cell death in a dose-dependent manner in the HT-22 cells by regulating HIF1a and cell death signaling. CDBT prevented neuronal cell death signals and DNA fragmentation due to the hypoxia condition. CDBT significantly reduced cellular oxidation, cell death signals, and caspase-3 activities due to microglial cell activations. Moreover, CDBT significantly ameliorated LPS-induced BV-2 cell activation and evoked cellular oxidation through the recovery of redox homeostasis.
\end{abstract}

Conclusions: CDBT cam be considered as a vital therapeutic agent against neuronal cell deaths. Further studies are required to reveal the other functions of CDBT in vivo or in the clinical field.

Key words: herbal medicine, hypoxia, cell death, neuronal oxidation, HT-22 cells

\section{Introduction}

The neuronal cell damages cause variety spectrums

· 투고일: 2019.05.31 심사일: 2019.07.05, 게재확정일: 2019.07.06

- Corresponding author: In-chan Seol Dept. of Internal Korean Medicine, Dunsan Korean Medicine Hospital of Daejeon University, 75, Daedeok-daero 176beon-gil, Seo-gu, Daejeon, Korea TEL: 82-42-470-9130 E-mail: seolinch@ dju.ac.kr of brain tissue damage related diseases. As a result of abnormal neuron injuries, brain tissue has been considerably gotten chances to incidence of variety diseases; represented by acute type of stroke, and neurodegenerations including Alzheimer' disease, Parkinson' disease, or Huntington' diseases as well. Among the above them stroke is one of the most considerable disease in global public health. In addition, the rates of incidence of stroke also has 
been steadily increased ${ }^{1}$. For instance, cerebral ischemic stroke has been already reached up to approximately $80 \%$ of all patients with stroke ${ }^{2-4}$. Various etiological conditions have been suggested to etiological factors of stroke, mainly due to neuronal cell death, metabolic disturbance, excitotoxicity, and inflammatory response by either acute or chronic types ${ }^{5}$. Moreover, blood vessel occlusion owing to a thrombus, an immediated rack of supplements of oxygen and glucose in to the brain tissue, especially cerebral areas ${ }^{6.7}$. The above causes are also closely associated with the neuronal cell death by direct or indirect mode. Therefore, understanding the pathological mechanisms of stroke, which is focused on the neuronal cell death is the most crucial issue to develop clinical therapeutics.

Therefore, some of therapeutics have been developed for preventing from continuous neuronal cell injuries due to stroke, such as Extracellular Vesicles and Gasdermin proteins ${ }^{8.9}$. Up to date, the oxidative stress and inflammation mediated neuronal cell injury is well evidenced to understand pathophysiological progressing of stroke in the brain tissue. During suffering from stroke, reactive oxygen species (ROS), which is a harmful molecule of free radicals, easily accumulated and exclusively react to cell membranes, DNA, and mitochondrial. Because of the above abnormal reactions, mitochondrial dysfunction, DNA fragments, and the misfolding of proteins are happened ${ }^{10-12}$. Additionally, brain is a main tissue to damage by oxidative stress owing to relative less oxygen consumption, lack of antioxidant component, and plenty of polyunsaturated fatty acid. Therefore, to reduce oxidative stress and enhance antioxidant components are mainly focused on the therapeutic accesses against stroke.

On the other hand, Traditional Korean Medicine
(TKM) has developed based on the clinical practice for thousand years. In TKM, stroke has been known to be caused by various Korean Medical etiologies such as "fire and heat” (火熱) “qi deficiency" (氣虛) "dampness and phlegm" (濕痰) and "blood stasis" (瘀血), and these days the stroke is mainly evoked by blockage of blood stream ${ }^{13}$. Recently, there are potent evidences well documented that herbal medicines are effective to treat stroke with pharmacological properties as well as correspond mechanisms ${ }^{12-16}$. Based on these recent clinical practice and studies of the TKM, a new herbal mixture has been prescribed including Gastrodia elata Blume, Codonopsis lanceolata (Siebold \& Zucc.) Benth. \& Hook. f. ex Trautv., Salvia miltiorrhiza Bunge, Curcuma longa L. (Zingiberaceae), and Astragalus mongholicus Bunge, (called, Chenmadansamgamibokhap-tang, CDBT) which known as effective for ischemic stroke. Gastrodia elata Blume could reduce neuron cell apoptosis via reducing neuron cell damage by free radical, inhibiting $\mathrm{Ca} 2+$ influx into cells and decreasing the neuron toxicity by counteracting glutamate effect ${ }^{17}$. Curcuma longa L. and Codonopsis lanceolata play a protective role in brain injury through its anti-oxidant and anti-inflammatory activities ${ }^{18.19}$. Tanshinone IIA, a major component of Angelicae Gigantis Radix, has a neuronal protective effect by inhibiting the activity of caspase-3 after hypoxic nerve injury and has anti-inflammatory effects by decreasing the expression level of TNF- $a$ and IL-1 $\beta^{20}$. Astragalus mongholicus Bunge can play an important role in improving the damage of ischemic brain tissue by increasing expression levels of VEGF and VEGF receptor- $2^{21}$. To investigate the pharmacological effects of CDBT and corresponded mechanisms, the CDBT was applied to protect hypoxia-induced neuronal cell death using mouse hippocampus neuronal cell line, 
HT-22 cells. In addition to explain the possible underlying mechanisms of CDBT oxidative stress and inflammation which were derived from microglial activation were also conducted in this study.

\section{Material and method}

\section{Materials}

\section{1) Preparations of CDBT}

The CDBT, which is a new prescribed herbal mixture with water extract, is composed of same amount of five different herbal plants including Gastrodia elata Blume, Codonopsis lanceolata (Siebold \& Zucc.) Benth. \& Hook. f. ex Trautv., Salvia miltiorrhiza Bunge, Curcuma longa L. (Zingiberaceae), and Astragalus mongholicus Bunge, respectively (Table 1). All herbal plants were obtained from the Dunsan Oriental
Hospital of Daejeon University. The herbal mixtures were boiled with distilled water $(\mathrm{DW})$ at $100{ }^{\circ} \mathrm{C}$ for $4 \mathrm{hrs}$ and filtered with 300 mesh filter $(50 \mu \mathrm{m})$. Condensing during $1 \mathrm{hr}$ of extraction, sample was placed under $-70{ }^{\circ} \mathrm{C}$ for at least $3 \mathrm{hrs}$ for the frozen extract processing. The frozen lyophilization was performed over than 72 hrs and sample was collected and weighed. The final yield was 8.96\%.

Table 1. Components of CDBT and Its Ratio

\begin{tabular}{cc} 
Herbal medicine samples & Amount \\
\hline Gastrodia elata Blume & 15 \\
Codonopsis lanceolata (Siebold \& Zucc.) & 15 \\
Benth. \& Hook. f. ex Trautv. & 15 \\
Salvia miltiorrhiza Bunge & 15 \\
Curcuma longa L. (Zingiberaceae) & 15 \\
Astragalus mongholicus Bunge & 75 \\
\hline Total &
\end{tabular}

Table 2. Quantitative Analysis of Chemicals from CDBT

\begin{tabular}{|c|c|c|c|c|}
\hline Chemical structure & Compounds & $\mathrm{RT}$ (min) & Wave length $(\mathrm{nm})$ & $\begin{array}{c}\text { Concentrations } \\
(\text { Mean } \pm S D, \mu g / m g)\end{array}$ \\
\hline & Rosmarinic acid & 21.6 & 280 & $0.47 \pm 0.007$ \\
\hline & Salvianolic acid B & 23.5 & 280 & $5.48 \pm 0.042$ \\
\hline & Tanshinone IIA & 48.3 & 280 & N.D \\
\hline
\end{tabular}

Quantitative analysis of major compounds from CDBT. The Rosmarinic acid and Salvianolic acid B those of two major compounds from CDBT (mainly from Salvia miltiorrhiza Bunge) were analyzed to quantify. N.D : not detect, $\mathrm{RT}$ : retention time, $\mathrm{SD}$ : standard deviation 
2) Fingerprinting analysis of CDBT

To identify the chemical features and reproducibility of the CDBT, fingerprinting analysis was performed using high-performance liquid chromatography-diode array detector-mass spectrometry (HPLC-DAD-MS) for either CDBT or its reference compounds; especially for Salvia miltiorrhiza Bunge with its well-matched chemical compounds including salvianolic acid B, rosmarinic acid and tanshinoe IIA, respectively. Briefly, after the dissolution (20 mg of CDBT and $0.01 \mathrm{mg}$ of three reference chemicals in $1 \mathrm{~mL} 50 \%$ methanol) with filtration, and then these formulations were subjected to HPLC analysis of Agilent 1100 series. A Phenomenex Prodigy C18 (4.6×250 mm; particle size $5 \mu \mathrm{m}$ ) column was eluted with solvents A (10\% acetonitrile in water containing $0.1 \%$ formic acid) and $B(D W)$ at a flow rate of $0.4 \mathrm{~mL} / \mathrm{min}$. Solutions of $15 \% \mathrm{~A}$ and $85 \% \mathrm{~B}$ were changed to $60 \%$ B for $30 \mathrm{~min}, 40 \%$ B for $40 \mathrm{~min}$, and 0\% B for $60 \mathrm{~min}$. The histograms and quantification analysis were obtained under the condition of 280 and $330 \mathrm{~nm}$ (Fig. $1 \mathrm{~A}$ to $\mathrm{C}$ ).

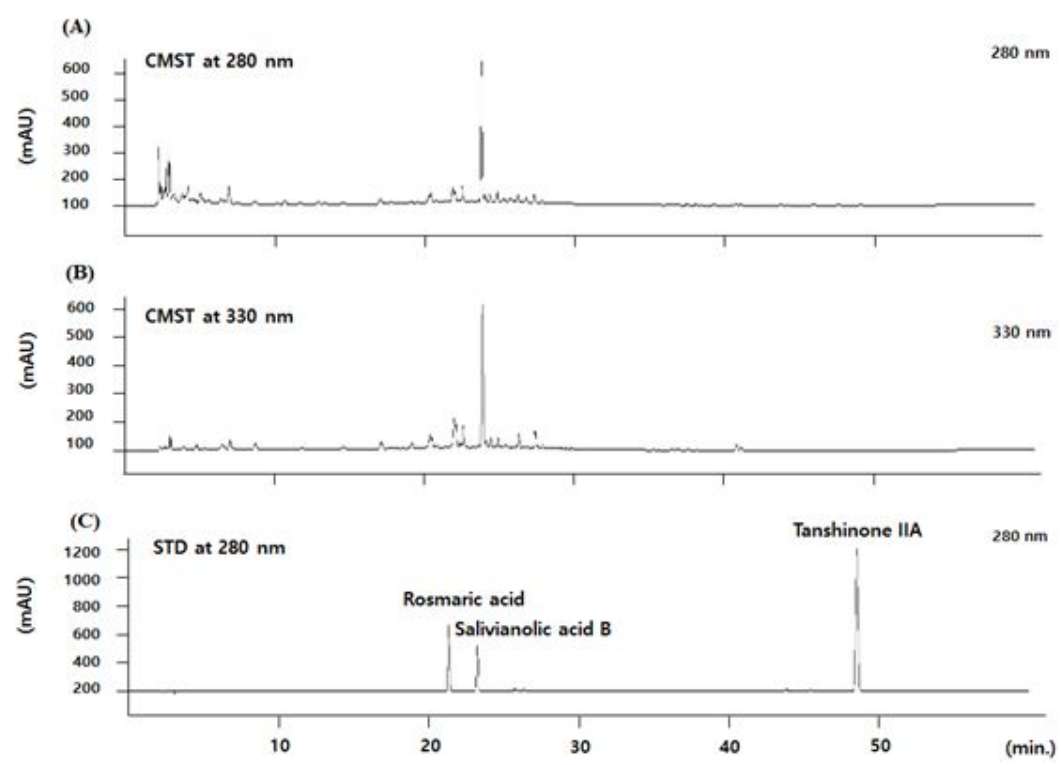

Fig. 1. Histogram of CDBT and its major compounds analysis.

CDBT and its major chemical compounds were adapted to the HPLC-DAD-MS under the condition of UV wave length of 280 and $330 \mathrm{~nm}$, to verify its chemical features or reproducibility. (A) Two-dimential histogram analysis of the CDBT under the $280 \mathrm{~nm}$ and (B) $330 \mathrm{~nm}$. (C) The chemical compounds of the CDBT, rosmaric acid and salvianolic acid were also analyzed at the same condition of the CDBT under the $280 \mathrm{~nm}$ of wavelength condition.

\section{Cell culture}

Mouse derived hippocampal neuronal and microglial cell lines, such as HT-22 cells and BV-2 cells, were obtained from the Department of anatomy from
Medical School of Chung-Nam-National University. The cells were cultured in DMEM with 10\% FBS and antibiotics (100 U/mL penicillin $\mathrm{G}$ and $100 \mu \mathrm{g} / \mathrm{mL}$ streptomycin). The cells were maintained under 
humidified conditions at $37{ }^{\circ} \mathrm{C}$ in $5 \% \mathrm{CO}_{2}$.

1) Cytotoxicity and cell proliferation analysis

Hypoxia condition was performed by oxygen and glucose deprivation/reperfusion (OGD/R) according to the previous methods using hypoxia chamber ${ }^{22}$. Briefly, the HT-22 cells $\left(3 \times 10^{3}\right)$ were seeded to 96-well microplates with 10\% FBS containing DMEM. Cells were pre-treated with various dose of the CDBT without/with hypoxia condition. For cytotoxicity effects of CDBT, cells were incubated $48 \mathrm{hrs}$ at concentrations given, and cell proliferation assay was performed under the condition of during $18 \mathrm{hrs}$ hypoxia and $2 \mathrm{hrs}$ recovery experiment.

2) Neuronal cell damage by hypoxia chamber

Neuronal cell damages were induced by OGD/R according to the previous methods ${ }^{22}$. HT-22 cells were cultured in a glucose-free DMEM, and then incubated with sealed air tight container. This condition resulted in a hypoxic atmosphere under the condition of absorbing oxygen and carbon dioxide productions. Then, cells were maintained in hypoxic conditions at $37{ }^{\circ} \mathrm{C}$ for 18 hours. After incubation, medium was discarded, and changed normal DMEM with glucose. Cells were further cultured for 2 hrs for re-oxygenation under normoxic condition to generate $\mathrm{OGD} / \mathrm{R}$. The cells cultured in growth culture medium under normoxic condition and served as a negative control through all hypoxic condition of neuronal cell experiment.

3) Microglia cells activation

In order to investigate the corresponded mechanisms of the CDBT, especially redox system homeostatis of neuronal cells and inflammation in microglial cells, BV-2 cells were activated by stimulation of LPS $(0.1 \mu \mathrm{g} / \mathrm{mL})$ or co-treatment with LPS $(0.1$ $\mu \mathrm{g} / \mathrm{mL})$ with IFN-y $(100 \mathrm{U} / \mathrm{mL})$ treatments. The BV-2 cells were seeded to the 24 well-plates as a density of $2 \times 10^{5}$ cells $/ \mathrm{mL}$, then incubated for overnight at the $37^{\circ} \mathrm{C}, 5 \% \quad \mathrm{CO}_{2}$ condition. The CDBT $(25,50$, and $100 \mu \mathrm{g} / \mathrm{mL})$ were treated to the cells prior to 4 hours of LPS treatment. After LPS treatment, cells were further incubated 24 hours then measured NO and inflammatory cytokines from cell culture medium. For microglial activation mediated neuronal cell damages, the prepared conditional medium from co-treatments of LPS and IFN- $\gamma$ were added to the HT-22 cell culture plates. After 18 hours of incubation, cellular oxidation and cell death signals were measured.

\section{Biochemical analysis}

1) Cellular oxidation analysis

Cellular oxidations of HT-22 cells with hypoxia condition or BV-2 cells activation was measured using CellROX® and dihydroethidium. Briefly, cells were seeded at a density of $5 \times 10^{5}$ cells in 60-mm of glass bottom dishes (Thermo) and treat the cells with the CDBT (50 and $100 \mu \mathrm{g} / \mathrm{mL}$ ) or ascorbic acid $(100 \mu \mathrm{g} / \mathrm{mL})$. Dose-dependent modes of CDBT were treated to the dishes 4 hrs prior to hypoxia condition or LPS stimuli. After then, further 30 min incubation with final concentration of $5 \mu \mathrm{M}$ of CellROX® reagent was added to the cells and medium was discarded A total 3 times of washing cells with PBS and fix with $3.7 \%$ formaldehyde for $15 \mathrm{~min}$, thereafter a nuclear counterstain with hochest, then permeabilize the cells with $0.5 \%$ Triton X-100 for $10 \mathrm{~min}$.

The cell permeable fluorogenic DHE was used to detect for the generations of superoxide radicals. A final concentration of $5 \mu \mathrm{M}$ of DHE in fresh DMEM medium was added and dishes were further incubated in the dark condition for $30 \mathrm{~min}$ at the $37{ }^{\circ} \mathrm{C}$. Then cells were washed with PBS at 
least two times.

After obtained all of stained sample, images were taken by fluorescence microscope (ZEIZZ). Images were analyzed using ImageJ free software. 200 cells of each samples were analyzed under the 630× magnification.

\section{2) Analysis of cellular images}

Cellular damages were captured appropriated images by performance of either immunohistochemistry (IHC) or immunofluorescence (IF) analysis. Briefly, the HT-22 cells were seeded at a density of $2.5 \times 10^{4}$ cells in 12 well plates and pre-treated with the CDBT (50 and $100 \mu \mathrm{g} / \mathrm{mL}$ ) or ascorbic acid (100 $\mu \mathrm{g} / \mathrm{mL}$ ), respectively. Then cells were put under the condition of $\mathrm{OGD} / \mathrm{R}$ hypoxia. After that cells were washed with PBS after entire removed medium and further incubated with $0.5 \%$ Triton X-100 for 10 min at RT. After incubation, the cells were fixed with 3.7\% formaldehyde for $15 \mathrm{~min}$, and with PBS two times. The cells were incubated using normal horse serum (2.5\%) for 1 hrs at RT, then added primary antibodies against Hypoxia-inducible factor (HIF)-1a (1:100), cytochrome c(1:100), 4-hydroxynonenal (4-HNE, 1:200), 8-hydroxy-2'-deoxyguanosine (8-OHdG, 1:100) inducible nitric oxidase (iNOS, $1: 100$ ), $\mathrm{Cu} / \mathrm{Mn}^{-}$ superoxide dismutase (SOD, 1:100), and caspase-3/7 (1:100), were incubated under the $4{ }^{\circ} \mathrm{C}$ for overnight, respectively.

For IHC analysis in the present study, the 8-OHdG and 4-HNE in HT-22 with hypoxia condition were developed and avidin-conjugated secondary antibody which were incubated at RT for $2 \mathrm{hrs}$, then the signals were enhanced by development with 3,3-diaminobenzidine (DAB). The positive signals were detected under the light microscopy condition.

For IF analysis, HIF-1a, cytochrome c, iNOS,
$\mathrm{Cu} / \mathrm{Mn}-\mathrm{SOD}$, 4-HNE, and caspase-3/7 were applied and fluorescence conjugated secondary antibodies (Green fluorescence for Aloxa 488 and red fluorescence for Aloxa 594) were added to slides (1:200 for each) and incubate $1 \mathrm{hr}$ at RT. Then washed with PBST solution (0.5\% Tween-20 in PBS) two times and PBS for one time. Nucleus counting staining was conducted with hochest and positive signals were obtained under the fluorescence microscopy condition.

Cell death signaling was detected using Terminal deoxynucleotidyl transferase (TdT) dUTP Nick-End Labeling (TUNEL) assay. The positive signals were detected after application of DAB then captured images under the light microscopy condition (Olympus, $\times 200$ magnification).

3) Measurement of nitric oxide (NO) contents

BV-2 cells were seeded at 24 well plates with intensity of $1 \times 10^{5}$ cells $/ \mathrm{mL}$. CDBT (25, 50, and $100 \mu \mathrm{g} / \mathrm{mL}$ ) and ascorbic acid were pre-treated to the plates 4 hrs before LPS (100 ng/mL) treatment, respectively. Then, plates were incubated at $37{ }^{\circ} \mathrm{C}$, $5 \% \mathrm{CO}_{2}$ condition for overnight. The nitric oxide (NO) level in cell culture medium was determined using the Griess' method $^{23}$. The final product of purple azo dye $t$ was measured at $540 \mathrm{~nm}$ using a UV spectrophotometer.

4) Measurement of pro-and anti-inflammatory cytokines

BV-2 cells were seeded at 24 well plates with intensity of $1 \times 10^{5}$ cells $/ \mathrm{mL}$. Various doses of CDBT and ascorbic acid were pre-treated to the plates 4 hrs before LPS $(100 \mathrm{ng} / \mathrm{mL})$ treatment. After LPS treatment, plates were incubated at $37{ }^{\circ} \mathrm{C}, 5 \%$ $\mathrm{CO}_{2}$ condition for overnight. The levels of tumor necrosis factor (TNF)-a, interlukin (IL)-1ß, IL-6, and IL-10 levels in cell culture medium were measured using commercial ELISA kits according to the 
manufacturers' instructions. The absorbance at 450 and $570 \mathrm{~nm}$ was measured using a spectrophotometer.

5) Cellular redox analysis

The biochemical analysis in the cellular levels were performed after obtained cell lysates which were prepared using commercial cell lysate reagents. The lipid peroxide levels were determined using thiobarbituric acid reactive substances (TBARS) as previously described ${ }^{24}$. The TBARS contents were displayed as a unit of $\mu \mathrm{M}$ malondialdehyde (MDA). Briefly, $50 \mu \mathrm{L}$ of cell lysates or standard samples were added to $500 \mu \mathrm{L}$ of $20 \%$ trichloroacetic acid (TCA) and then mixed with $200 \mu \mathrm{L}$ of $0.67 \%$ thiobarbituric acid (TBA), followed by heating at $100{ }^{\circ} \mathrm{C}$ for $45 \mathrm{~min}$, cooling on ice and vigorously vortexing with $800 \mu \mathrm{L}$ of $\mathrm{n}$-butanol. After centrifugation at $12,000 \times \mathrm{g}$ for $15 \mathrm{~min}$, the absorbance of the upper organic layer was measured at $520 \mathrm{~nm}$ using UV spectrophotometer and compared with a 1, 1, 3, 3-tetraethoxypropane (TEP) standard curve.

The total glutathione (GSH) content was determined as detection of total thiol contents ${ }^{25}$. Fifty of diluted cell lysate samples or total GSH was combined with $80 \mu \mathrm{L}$ of a DTNB/NADPH mixture $(10 \mu \mathrm{L}$ of $4 \mathrm{mM}$ DTNB and $70 \mu \mathrm{L}$ of $0.3 \mathrm{mM}$ NADPH) in a 96-well microplate. Next, $20 \mu \mathrm{L}(0.06 \mathrm{U})$ of a GSH-reductase (GSH-Rd) solution was added to each well. The reactions were read under the 412 nm of wave.

Catalase activity was assayed followed by color reaction method as previously mentioned ${ }^{26}$. Briefly, $150 \mu \mathrm{L}$ of phosphatase buffer (250 mM, pH 7.0), $150 \mu \mathrm{L}$ of $12 \mathrm{mM}$ methanol and $30 \mu \mathrm{L}$ of hydrogen peroxide were mixed with $300 \mu \mathrm{L}$ of the serum sample or standard solutions in a $13 \times 100 \mathrm{~mm}$ test tube. The reaction was allowed to proceed for 10 to $20 \mathrm{~min}$ and was stopped by the addition of 450 $\mu \mathrm{L}$ of Purpald solution (22.8 mM Purpald in $2 \mathrm{~N}$ potassium hydroxide). The mixture was left for 20 min at $25{ }^{\circ} \mathrm{C}$, followed by the addition of $150 \mu \mathrm{L}$ of potassium periodate. The absorbance of the purple formaldehyde adduct was measured at 558 nm using a spectrophotometer.

6) Analysis of caspase- 3 activities

The microglial cell activation mediated neuronal cell death was measured by caspase- $3 / 7$ activities using commercial kit (CaspACETM Assay System, Colorimetric, Promega). Briefly, HT-22 cells were seeded to the 6 -well plate as a density of $1 \times 10^{6}$ cells/well, then the CDBT (25, 50, and $100 \mu \mathrm{g} / \mathrm{mL}$ ) or ascorbic acid $(100 \mu \mathrm{g} / \mathrm{mL})$ prior to 4 hours of conditional media treatment, and further incubated for 18 hrs. The procedures were followed to manufacture' protocol.

\section{Statistical analysis}

All data are expressed as the mean \pm standard deviation (SD). Statistically significant differences between the groups were analyzed by one-way analysis of variance (ANOVA) followed by post hoc multiple comparison Fisher's LSD t-test using the IBM SPSS statistics 20.0 (SPSS Inc. Chicago, IL, USA). Differences at $p<0.05, p<0.01$, or $p<0.001$ were considered statistically significant.

\section{Results}

1. Cytotoxicity effects of CDBT on HT-22 cells Various concentrations of CDBT (from $7.8 \mu \mathrm{g} / \mathrm{mL}$ to $500 \mu \mathrm{g} / \mathrm{mL}$, as mode of serial dilutions) were treated to the HT-22 cells and incubated for 48 hours. Till the concentration of $62.5 \mu \mathrm{g} / \mathrm{mL}$ HT-22 cells were not influenced by the CDBT treatments, but since $125 \mu \mathrm{g} / \mathrm{mL}$, CDBT showed cytotoxicity 
to the normal condition of HT-22cells (Fig. 2).

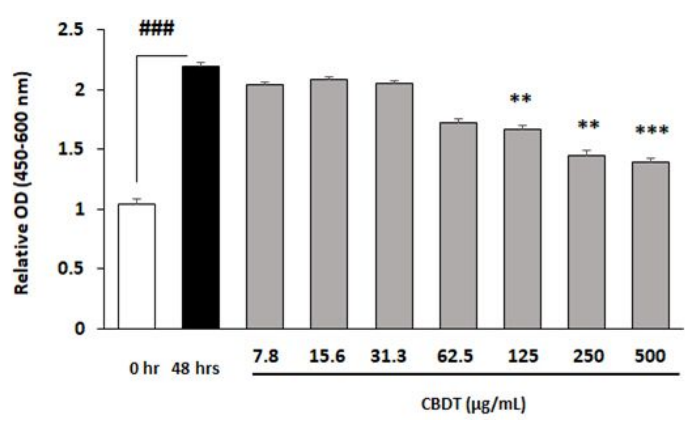

Fig. 2. Cytotoxicity effects of CDBT on the HT-22 cells.

HT-22 cells were seeded to the 96-well microplate at a density of $3 \times 10^{3}$ cells/well. After overnight of incubation, variety concentrations of CDBT were treated to the cells. The cytotoxicity assay was analyzed after further 48 hours of incubation with the CDBT. Incubation of overnight, various concentrations of CDBT were treated to the HT-22 cells and cytotoxicity was measured after $48 \mathrm{hrs}$ incubation with CDBT. ${ }^{\# \#} \mathrm{p}<0.001$ vs. $0 \mathrm{hr},{ }^{* *} \mathrm{p}<0.01$, and ${ }^{* * *} \mathrm{p}<0.001$ vs. Normal

2. Cell proliferation assay of CDBT on Hypoxiainduced HT-22 cells

To obtain the protective effects of CDBT against neuronal cell death, cell proliferation analysis under the hypoxia condition was performed. Since the dose of $32.5 \mu \mathrm{g} / \mathrm{mL}$ of the CDBT pre-treatment showed significant protect effects of the HT-22 cells from hypoxia condition. From this dosage to $250 \mu \mathrm{g} / \mathrm{mL}$, pre-treatment with CDBT significantly deterred neuronal cell death against hypoxia condition (Fig. 3). Interestingly, the concentration at a 500 $\mu \mathrm{g} / \mathrm{mL}$ also showed significant pharmacological properties, but not similar with $250 \mu \mathrm{g} / \mathrm{mL}$ dose.

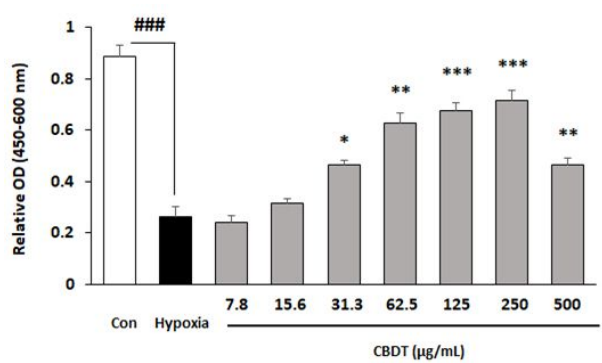

Fig. 3. Cell proliferation assay of CDBT on the hypoxia-induced neuronal cell damage.

HT-22 cells were seeded to the 96-well microplate at a density of $1 \times 10^{4}$ cells/well. Various concentrations of CDBT were treated to the HT-22 cells 4 hours prior to hypoxia. After $18 \mathrm{hrs}$ plates were move to reperfusion of oxygen supply then cell proliferation assay was measured. \#\#\#<0.001 vs. control, *p<0.05, $* * p<0.01$, and $* * * p<0.001 v s$. Hypoxia condition, respectively.

\section{Effects of CDBT against hypoxia-induced neuronal} cell death

Hypoxia condition, especially the method of $\mathrm{OGD} / \mathrm{R}$ well induced HIF-1a in cellular levels. The programmed cell death signal molecule, cytochrome $c$ was also correspondly increased depends on the HIF-1a expression which were evidenced by IF analysis (Fig. 4). Pre-treatment with CDBT, while notably reduced theses deterations of both HIF-1a and cytochrome c, respectively (Fig. 4).

TUNEL assay well exhibited the neuronal cell death of the HT-22 cells by analysis of OGD/R (Fig. 5). Pre-treatment with the CDBT (50 and $100 \mu \mathrm{g} / \mathrm{mL}$ ) obviously showed its anti-cell death efficacies on the hypoxia-induced neuronal cell death (Fig. 5). Ascorbic acid was used as positive control in this experiment, and showed similar effects on the HIF-1a, cytochrome c, and TUNEL assay. 


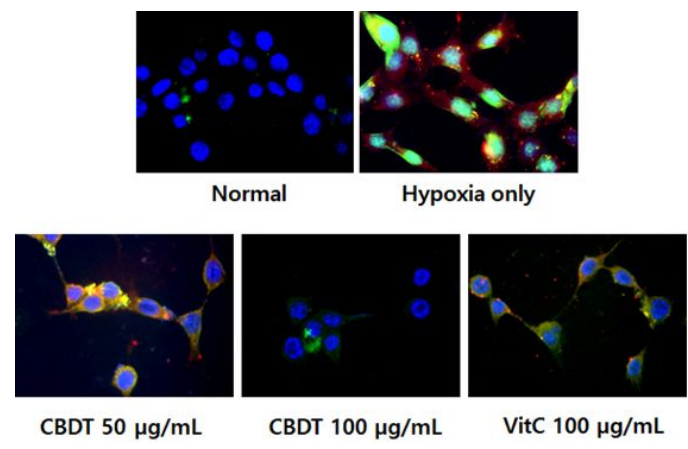

Fig. 4. Effect of CDBT on the hypoxia-induced HIF-la and cytochrome $\mathrm{C}$.

HT-22 cells were seeded at a density of $5 \times 10^{5}$ cells in $60-\mathrm{mm}$ glass bottom dishes and treat the cells with the CDBT (50 and $100 \mu \mathrm{g} / \mathrm{mL}$ ) or ascorbic acid $(100 \mu \mathrm{g} / \mathrm{mL})$. Then cells were undergone $\mathrm{OGD} / \mathrm{R}$ condition. Green fluorescence for detecting against HIF-1a using Alexa-488 conjugated secondary antibody (detect as green fluorescence) and red fluorescence for detecting against cytochrome c using Alexa-4594 conjugated secondary antibody (detect as red fluorescence), respectively. Immunofluorescence images were analyzed under the fluorescence microscopy circumstance (×630 magnification).

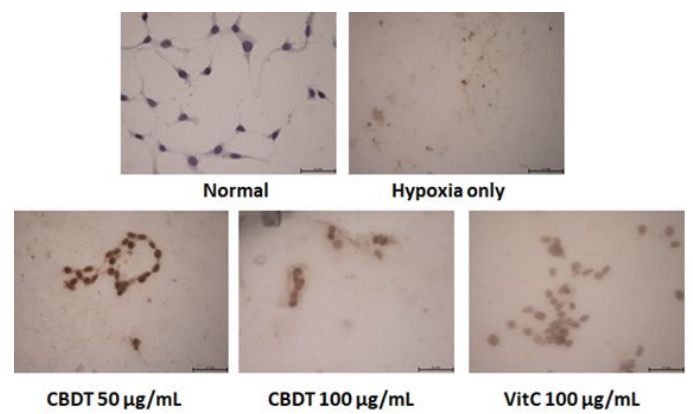

Fig. 5. Effect of CDBT on the hypoxia-induced HT-22 cell death.

HT-22 cells were seeded at a density of $5 \times 10^{5}$ cells in $60-\mathrm{mm}$ glass bottom dishes and treat the cells with the CDBT (50 and $100 \mu \mathrm{g} / \mathrm{mL}$ ) or ascorbic acid $(100 \mu \mathrm{g} / \mathrm{mL})$. Then cells were undergone $\mathrm{OGD} / \mathrm{R}$ condition. The cell death signals were obtained by performance of TUNEL assay.

\section{Effects of CDBT against hypoxia-induced neuronal} cell injury

IF analysis of a potent cell death related molecules, cleaved-caspase-3 positive signals were drastically enhanced owing to $\mathrm{OGD} / \mathrm{R}$ of hypoxia condition (Fig. 6). On the other hand, pre-treatment with the CDBT promptly reduced the positive signals. Ascorbic acid was used as positive control in this experiment.

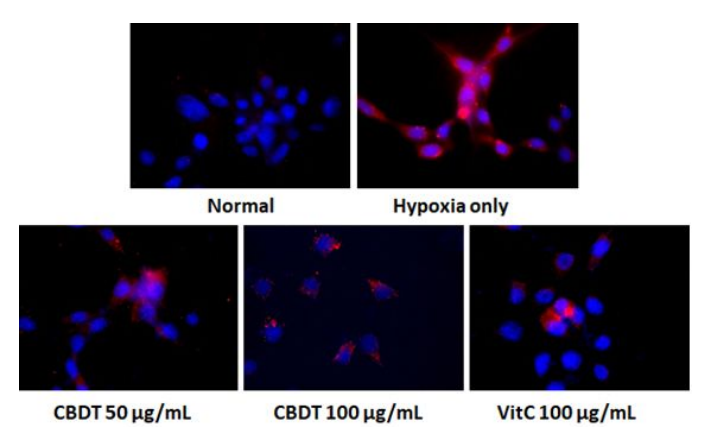

Fig. 6. Effect of CDBT on the hypoxia-induced neuronal cell death.

HT-22 cells were seeded at a density of $5 \times 10^{5}$ cells in $60-\mathrm{mm}$ glass bottom dishes and treat the cells with the CDBT (50 and $100 \mu \mathrm{g} / \mathrm{mL}$ ) or ascorbic acid $(100 \mu \mathrm{g} / \mathrm{mL})$. Then cells were undergone $\mathrm{OGD} / \mathrm{R}$ condition. The positive signals of cleaved caspase- 3 was detected by Alexa-594 conjugated secondary antibody. Immunofluorescence analysis under the fluorescence microscopy circumstance (×630 magnification).

\section{Effects of CDBT against hypoxia-induced DNA fragmentation}

Fig. 7 displayed that the pharmacological effects of CDBT on the DNA fragmentation by OGD/R of hypoxia condition. Pre-treatment with the CDBT, however dramatically attenuated DNA fragmentations. Ascorbic acid was used as positive control in this experiment. 


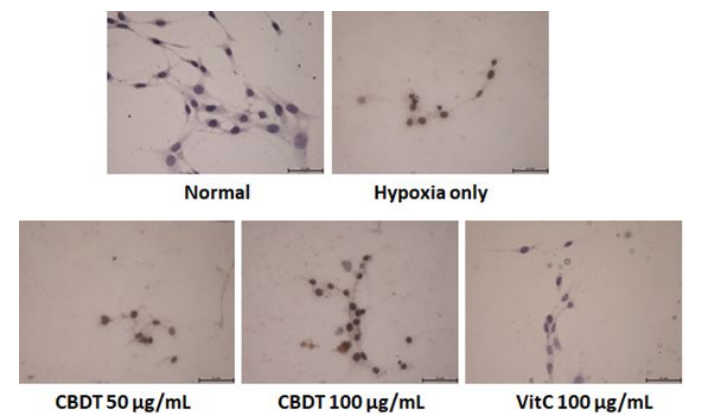

Fig. 7. Effect of CDBT on the hypoxia-induced DNA fragmention of HT-22.

HT-22 cells were seeded at a density of $5 \times 10^{5}$ cells in $60-\mathrm{mm}$ glass bottom dishes and treat the cells with the CDBT (50 and $100 \mu \mathrm{g} / \mathrm{mL}$ ) or ascorbic acid $(100 \mu \mathrm{g} / \mathrm{mL})$. Then cells were undergone $\mathrm{OGD} / \mathrm{R}$ condition. The positive DNA fragmentation signals of $8-0 \mathrm{HdG}$ were obtained by IHC analysis.

\section{Effects of CDBT against hypoxia-induced neuronal cell oxidation}

\section{1) IF analysis of 4-HNE}

The final product of cellular oxidation was measured by IF analysis of 4-HNE, which is a potent marker of lipid peroxidation. Positive signals of the 4-HNE was strongly enhanced by hypoxia, whereas pre-treatment with the CDBT notably reduced the 4-HNE signals (Fig. 8). Ascorbic acid was used as positive control in this experiment.

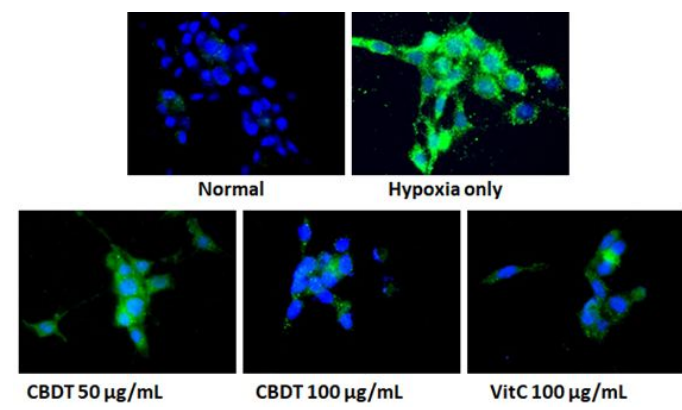

Fig. 8. Effect of CDBT on the hypoxia-induced neuronal cell oxidation.

HT-22 cells were seeded at a density of $5 \times 10^{5}$ cells in 60-mm glass bottom dishes and treat the cells with the CDBT (50 and $100 \mu \mathrm{g} / \mathrm{mL}$ ) or ascorbic acid $(100 \mu \mathrm{g} / \mathrm{mL})$. Then cells were undergone $\mathrm{OGD} / \mathrm{R}$ condition. The final product of cellular oxidation, 4-HNE, was detected by Alexa-488conjugated secondary antibody. Immunofluorescence images were analyzed under the fluorescence microscopy circumstance (×630 magnification).

\section{2) Cellular oxidations assays}

Whether the ROS led to mediate neuronal cell injury or not, cellular oxidation analysis was performed by both CellROX and DHE stainings. Hypoxia caused drastic increases of both CellROX and DHE signals, while pre-treatment with the CDBT decreased those of abnormal enhanced signals (Fig. 9). Ascorbic acid was used as positive control in this experiment.
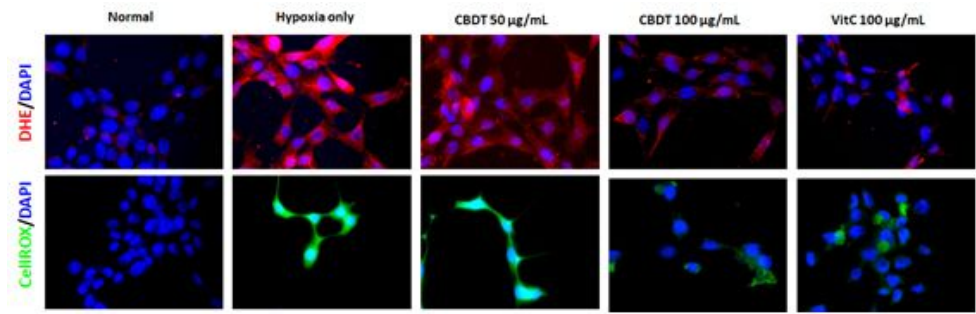

Fig. 9. Cellular oxidations assays.

HT-22 cells were seeded at a density of $5 \times 10^{5}$ cells in $60-\mathrm{mm}$ glass bottom dishes and treat the cells with the CDBT (50 and $100 \mu \mathrm{g} / \mathrm{mL})$ or ascorbic acid $(100 \mu \mathrm{g} / \mathrm{mL})$. Then cells were undergone OGD/R condition. Cellular oxidations were performed using DHE for detecting superoxide radicals (Red fluorescence, upper panel), and CellROX dye (For green fluorescence, bottom panel). Images were captured under the fluorescence filter equipped microscopy condition (×630 magnification). 
7. Anti-Oxidant Effects of CDBT on the hypoxiainduced neuronal cell oxidation

To determine anti-oxidant effect of CDBT against hypoxia-induced neuronal cell injury, IF analysis of $\mathrm{Cu} / \mathrm{Zn}-\mathrm{SOD}$ was performed. Pre-treatment with CDBT displayed its pharmacological properties by drastically increases of $\mathrm{Cu} / \mathrm{Zn}$-SOD positive signals. On the other hand, hypoxia condition severely deterred the positive signals of $\mathrm{Cu} / \mathrm{Zn}-\mathrm{SOD}$ (Fig. 10). Ascorbic acid was used as positive control in this experiment.

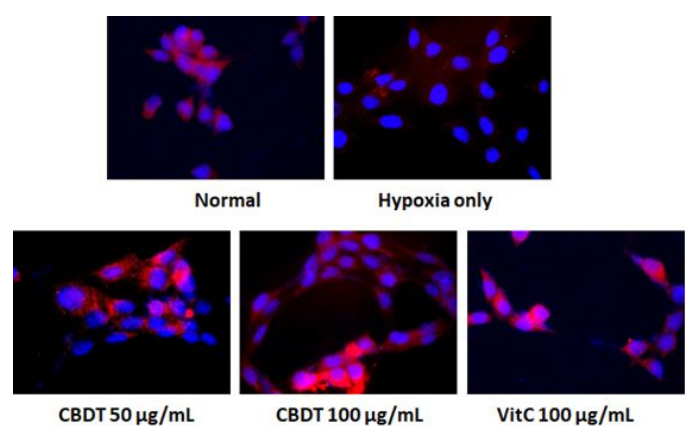

Fig. 10. Effect of CDBT on the hypoxia-induced neuronal cell oxidation.

HT-22 cells were seeded at a density of $5 \times 10^{5}$ cells in $60-\mathrm{mm}$ dishes and treat the cells with the CDBT (50 and $100 \mu \mathrm{g} / \mathrm{mL}$ ) or ascorbic acid $(100 \mu \mathrm{g} / \mathrm{mL})$. Then cells were undergone OGD/R condition. $\mathrm{Cu} / \mathrm{Zn}-\mathrm{SOD}$ was detected by IF analysis under the fluorescence microscopy circumstance (×630 magnification).

8. CDBT ameliorates microglia cells activation mediated neuronal cell damage

1) Effects of CDBT on oxidation by BV-2 cell activation

As comparing to the normal group, LPS (100 $\mathrm{ng} / \mathrm{mL}$ ) caused higher increases of CellROX® positive signals, while pre-treatment with the CDBT slightly decreased those of signals with LPS treated group (Upper panel of Fig. 11). To explain the activation of inflammatory response and oxidative stress from microglial cells, BV-2 cells were treated to the LPS (100 ng/mL) for microglial cells activation. LPS (100 $\mathrm{ng} / \mathrm{mL}$ ) considerably increased the DHE intensity as compared with normal group, whereas CDBT slightly decreased those of ROS generations as compared with LPS treated group (Bottom panel of Fig. 11). Ascorbic acid was used as positive control in this experiment.
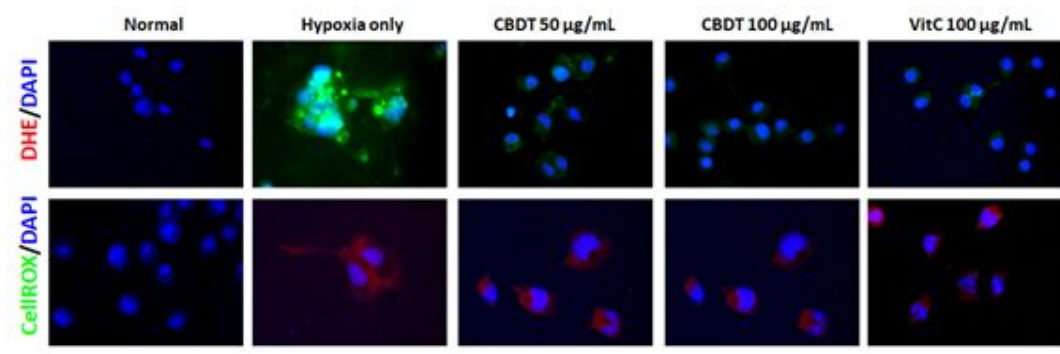

Fig. 11. Effects of the CDBT on the LPS-induced BV-2 cell activation.

BV-2 cells were seeded at a density of $5 \times 10^{5}$ cells in $60-\mathrm{mm}$ dishes and treat the cells with the CDBT (50 and $100 \mu \mathrm{g} / \mathrm{mL})$ or ascorbic acid $(100 \mu \mathrm{g} / \mathrm{mL})$. Then cells were treated LPS $(100 \mathrm{ng} / \mathrm{mL})$ for overnight $(18 \mathrm{hrs})$. Cellular oxidation that was from microglial cells activations were detected by CellROX® analysis. Images were captured under the circumstance ( $\times 630$ magnification). 
2) Effects on the microglial activation mediated neuronal cell injuries

To investigate the corresponded mechanisms of the CDBT on the neuronal cell death, microglial activation and its mediated neuronal cell damages were determined. Pre-treatment with the CDBT considerably reduced NO levels in the medium, as compared with LPS only group (Fig. 12-A). Additionally, treatment with thee conditional medium led to abnormal increases of TBARS contents as compared with normal group, while pre-treatment with the
CDBT significantly ameliorated that of abnormal TBARS levels (Fig. 12-B).

As a potent antioxidant component, total GSH was sharply decreased due to hypoxia condition, and catalase which is one of the most outstanding antioxidant enzymes were also deterred its activities by hypoxia condition. Pre-treatment with the CDBT significantly exerted to prevent from these abnormal deteriorations (Fig. 12-C, D). Ascorbic acid which was used as a positive control in this study showed similar effects.
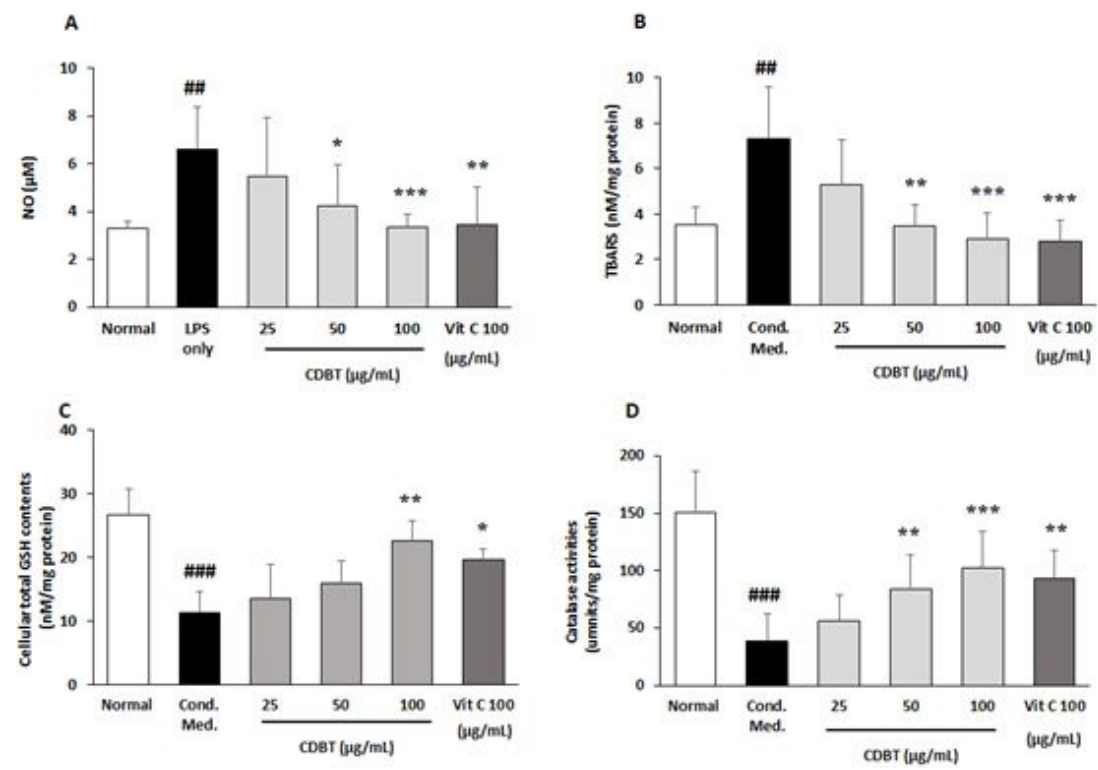

Fig. 12. Effects of CDBT on Redox signals.

The conditional medium which was from BV-2 activation was added to the HT-22 cells for 18 hours, after pre-treatment of CDBT $(25,50$, and $100 \mu \mathrm{g} / \mathrm{mL})$ or ascorbic acid $(100 \mu \mathrm{g} / \mathrm{mL})$. After completion of incubation under the $37{ }^{\circ} \mathrm{C}, 5 \% \mathrm{CO}_{2}$ condition. NO levels were measured in the BV-2 cell with LPS treatment condition of medium levels (A). Other parameters including TBARS (B), total GSH contents (C), and catalase activities (D) were determined in the cellular protein levels of HT-22 cells which were damaged by conditional media treatment. Data were expressed as mean \pm SD. \# ${ }^{\#}<0.01$, \#\#\# ${ }^{\#}<0.001$ vs. Normal, ${ }^{*} p<0.05,{ }^{*} p<0.01$, and ${ }^{* * *} p<0.001$ vs. Conditional medium, respectively. 
3) Effects on the microglial active inflammatory reactions

Next experiment was performed to investigate the pharmacological properties of the CDBT on microglial cell activation. LPS was treated to the BV-2 cells after 4 hours the CDBT or ascorbic acid. The LPS only group showed significant increases of TNF-a levels in medium as compared with normal group, whereas pre-treatment with the CDBT significantly lowered the elevated NO levels as compared with LPS only group (Fig. 13-A). Other pro-inflammatory cytokines, such as IL1- $\beta$ and IL-6 were also significantly higher than that of normal group, but decreased these elevated cytokine levels in the pre-treatment with CDBT groups as compared with LPS only group (Fig. 13-B, C). On the other hand, the pre-treatment with CDBT significantly exerted to prevent from deletion of IL-10, which is an anti-inflammatory cytokine against LPS treatment (Fig. 13-D). Pre-treatment with ascorbic acid showed similar effects of the CDBT.
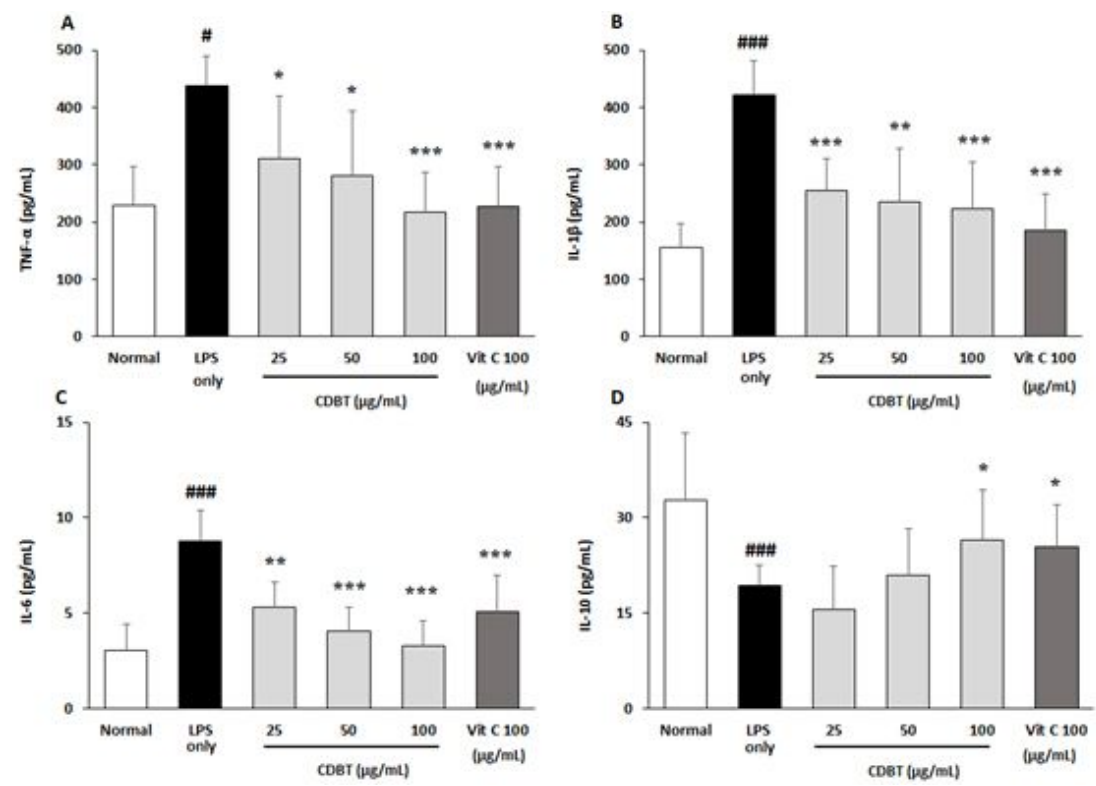

Fig. 13. Effects of CDBT on pro- and anti-inflammatory cytokines.

The conditional medium which was from BV-2 activation was added to the HT-22 cells for 18 hours, after pre-treatment of $\operatorname{CDBT}(25,50$, and $100 \mu \mathrm{g} / \mathrm{mL})$ or ascorbic acid $(100 \mu \mathrm{g} / \mathrm{mL})$. After completion of incubation under the $37{ }^{\circ} \mathrm{C}, 5 \% \mathrm{CO}_{2}$ condition. After completion of incubation the supernatant of cell culture medium was collected and inflammatory cytokines including TNF-a (A), IL-1 $\beta$ (B), IL-6 (C), and IL-10 (D) in the medium levels were measured by ELISA method. Data were expressed as mean \pm SD. ${ }^{\#} p<0.5$, \#\#\# $<<0.001$ vs. Normal, ${ }^{*} \mathrm{p}<0.05,{ }^{* *} \mathrm{p}<0.01$, and $* * * \mathrm{p}<0.001$ vs. Conditional medium, respectively. 
9. Effects on the microglial cell activation mediated neuronal cell damages.

To verify the pharmacological effects of CDBT on the neuronal cell death owing to microglial cell activation, conditional medium was prepared by treated with LPS $(100 \mathrm{ng} / \mathrm{mL})$ and IFN-y (100 $\mathrm{U} / \mathrm{mL}$ ) to the BV-2 cells. Conditional media exerted to significantly elevate caspase- 3 activities in the HT-22 as compared with normal group ( $p<0.001)$, whereas pre-treatment with CDBT significantly decreased those higher alterations of caspase- 3 activities as compared with conditional media only treated group (Fig. 14).

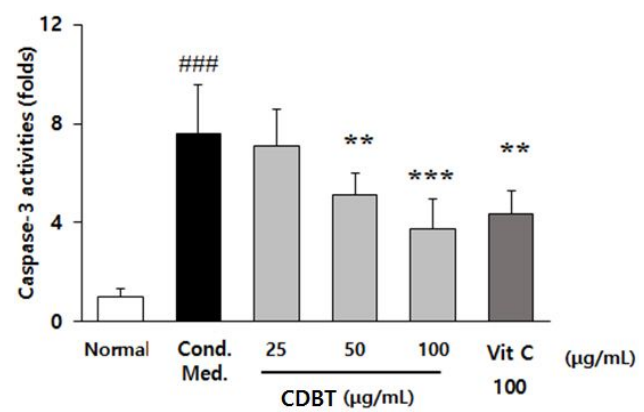

Fig. 14. Effects of CDBT on the neuronal cell death by microglial cells activation.

Conditional medium of microglial cell activation by treatment with LPS $(100 \mathrm{ng} / \mathrm{mL})$ with IFN-y $(100 \mathrm{U} / \mathrm{mL})$. HT cells were splited to the 6 well-plate as a density of $1 \times 10^{6}$ cells $/ \mathrm{mL}$ and pre-treatment with $\mathrm{CDBT}$ (25, 50, and $100 \mu \mathrm{g} / \mathrm{mL})$ or ascorbic acid (100 $\mu \mathrm{gmL})$ during 4 hrs before adding to conditional media treatment. Then plates were incubated to the cell incubator (37 ${ }^{\circ} \mathrm{C}, 5 \% \mathrm{CO}_{2}$ supplement condition). After $18 \mathrm{hrs}$ incubation, cell lysates were obtained, and caspase- 3 activities were measured. Data were expressed as mean \pm SD. \#\#p $<0.001$ vs. Normal, ${ }^{* *} p<0.01$, and ${ }^{* * *} \mathrm{p}<0.001$ vs. Conditional medium, respectively.

\section{Discussion}

To date, there are many of etiological factors participate to accomplish hypoxia including oxidative stress, inflammation, and limitation of nutrition supplement. In addition, the hypoxia is complexly associated with various neuronal disorders regardless of acute or chronic types. This disease condition only exerted to the acute type of brain tissue damage such as stroke, but also caused neurodegenerations such as Alzheimer's diseases, Parkinson's diseases, or Huntington' diseases ${ }^{27}$. Regarding the stroke, especially, it ranks as a second cause of death in the world. In addition, recent evidences well reported some of risk factors such as obesity, hypertension, smoking, abnormal diet habit, and lack of physical activities are caused incidence of stroke ${ }^{28,29}$.

Although the pathophysiological characters of hypoxia still remain unclear in recent days, but neuronal cell damages from oxidative stress and inflammation would thought generally up to date ${ }^{30,31}$. Additionally, the neuronal cell injuries due to microglial cell activation was also focused on to deeply understand hypoxia related neuronal diseases ${ }^{32.33}$. Thus, many of novel therapeutics on the hypoxia has been considered to modulate both oxidative stress and inflammation.

On the other hand, the TKM has been developed various treatment ways to treat hypoxia related disease, especially stroke with acupunctures and herbal medicines. Among the herbal medicines, some of previous studies well evidenced that they would useful to treat stroke by hypoxia. However, it is still needed to solve the underlying corresponded mechanisms of properties. Therefore, this study was performed to access the possibility using of herbal medicine to treat hypoxia-related stroke ${ }^{34-36}$. 
Based on the accumulated clinical practice, the herbal prescription of the CDBT was invented and applied mouse derived neuronal cell line, HT-22 cells under the hypoxia condition.

In the present study, firstly observed the possible cytotoxicity dose, and up to $125 \mu \mathrm{g} / \mathrm{mL}$ dosage of the CDBT, it didn't show the cytotoxicity in the normal cell culture condition and showed anti-cell death efficacies against the hypoxia condition as well (Fig. 2 and 3). According to these results, in the present study was performed the effective dose of the CDBT as 25, 50, and $100 \mu \mathrm{g} / \mathrm{mL}$. In addition, the neuronal cell of HT-22 model in the present study by $\mathrm{OGD} / \mathrm{R}$ of hypoxia condition was well worked. Hypoxia only group considerably enhanced the positive signal (Part of green fluorescence, HIF-1a), and pre-treatment with the CDBT drastically blocked that of abnormal increases of HIF-1a signals in the HT-22 cells. Additionally, the cell death signals of cytochrome c release were also well correlated to the HIF-1a, but not pre-treatment with the CDBT (Fig. 4).

The oxidative stress and its related cell death signals were considerably enhanced by evidence of 4-HNE staining as well as TUNEL assay (Fig. 5 and 8). Additionally, the neuronal cell injury due to severe oxidative stress in the hypoxia condition was also considerably increased cell death signals such as releasing of cytochrome $c$ as well as cleaved caspase-3 (Fig. 6). The DNA fragmentation, which is a corresponding potent marker of both cell death and oxidation, was also severely evoked concurrently as an evidence of $8-\mathrm{OHdG}$ IHC analysis (Fig. 7). Pre-treatment with the CDBT also exerted to reduce the abnormal enhancement of the cellular oxidations owing to abnormal increases of ROS signals which were detected by CellROX and
DHE (Fig. 9). These pathological alterations were significantly prevented from pre-treatment with the CDBT. Regarding antioxidant effects of the CDBT, it considerably prevented from the notable depletion of the $\mathrm{Cu} / \mathrm{Zn}-\mathrm{SOD}$ signals under the hypoxia condition (Fig. 10).

Particularly, brain tissue is well known for vulnerable organs to oxidation owing to high rate of oxygen consumptions, full of polyunsaturated fatty acids, easily transited metal irons, and sensitivity of blood-brain endothelial cells ${ }^{37-39}$. In addition, another cell types of brain tissue, such as either amygdala or microglials are also deeply related to the progression of neuronal cell damages ${ }^{40}$. Thus, next experiment was performed for focusing on the microglial cell activation-induced neuronal cell death. Conditional media was prepared by co-stimuli condition of the LPS with IFN-y in the BV-2 cells, then treated to the HT-22 cells.

Evidenced by the NO levels in the media and cellular oxidations (Fig. 11 and 12-A) due to the microglial cell activations. All of results towards to the microglial cell activation-induced also concurrently arose which were evidenced by increases of TBARS, depletion of total GSH content, and deteriorations of catalase activities, respectively. Pre-treatment with the CDBT, however, significantly prevented most of the above abnormalities (Fig. 12-B to D). Particularly, pro-and anti-inflammatory cytokines were also normalized by pre-treatment with the CDBT as well (Fig. 13-A to D). Neuronal cell death was happened by microglial cells activation and the CDBT efficiently prevented from it as shown by caspase- 3 activities.

Interestingly, the most chemicals such as rosmarinic acid and salvianolic acid were in Salvia miltiorrhiza Bunge. from the CDBT. This herbal plants were 
most popularly used to treat blood stream blood stream-related dysfunction such as "dampness and

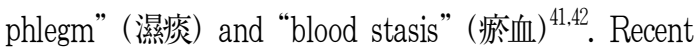
accumulated studies also well documented that the pharmacological properties of Salvia miltiorrhiza Bunge. in various brain diseases ${ }^{43-45}$.

Taken together, the CDBT showed protective effects on the hypoxia-induced neuronal cell damages and the underlying mechanisms were related to the relieving of oxidative stress mediated cell death signals.

\section{References}

1. Winek K, Engel O, Koduah P, Heimesaat MM, Fischer A, Bereswill S, et al. Depletion of Cultivatable Gut Microbiota by Broad-Spectrum Antibiotic Pretreatment Worsens Outcome After Murine Stroke. Stroke 2016;47(5):1354-63.

2. Donnan GA, Fisher M, Macleod M, Davis SM. Stroke. Lancet 2008:371(9624):1612-23.

3. Paraskevas KI. Secondary prevention of stroke. Lancet 2008:372(9643):1036.

4. Lee JC, Kim WK. Aging and Stroke. Kor $J$ Gerontol 2006;16:11-6.

5. Li P, Shen M, Gao F, Wu J, Zhang J, Teng F, et al. An Antagomir to MicroRNA-106b-5p Ameliorates Cerebral Ischemia and Reperfusion Injury in Rats Via Inhibiting Apoptosis and Oxidative Stress. Mol Neurobiol 2017:54(4):2901-21.

6. Genovese T, Mazzon E, Paterniti I, Esposito E, Bramanti P, Cuzzocrea S. Modulation of NADPH oxidase activation in cerebral ischemia/reperfusion injury in rats. Brain Res 2011;1372:92-102.

7. Zhou L, Bondy SC, Jian L, Wen P, Yang F, Luo $\mathrm{H}$, et al. Tanshinone IIA attenuates the cerebral ischemic injury-induced increase in levels of GFAP and of caspases-3 and -8. Neuroscience 2015:288:105-11.

8. Chen S, Mei S, Luo Y, Wu H, Zhang J, Zhu J. Gasdermin Family: a Promising Therapeutic Target for Stroke. Transl Stroke Res 2018 Dec; $9(6): 555-63$.

9. Puig B, Brenna S, Magnus T. Molecular Communication of a Dying Neuron in Stroke. Int $J \mathrm{Mol} S \mathrm{Sc}$ 2018;19(9) :2834.

10. Mao XY, Zhou HH, Li X, Liu ZQ. Huperzine A Alleviates Oxidative Glutamate Toxicity in Hippocampal HT22 Cells via Activating BDNF/TrkB-Dependent PI3K/Akt/mTOR Signaling Pathway. Cell Mol Neurobiol 2016;36(6):915-25.

11. Song J, Park J, Oh Y, Lee JE. Glutathione suppresses cerebral infarct volume and cell death after ischemic injury: involvement of F0X03 inactivation and Bcl2 expression. Oxid Med Cell Longev 2015;2015:426069.

12. Xu Y, Wang Y, Wang G, Ye X, Zhang J, Cao G, et al. YiQiFuMai Powder Injection Protects against Ischemic Stroke via Inhibiting Neuronal Apoptosis and PKCdelta/Drp1-Mediated Excessive Mitochondrial Fission. Oxid Med Cell Longev 2017:2017:1832093.

13. Nationwide College of Korean Medicine Faculty Council of Cardiology Internal Medicine. Cardiovascular and Neurological Medicine in Korean Medicine I. Seoul: Goonja; 2010, p. 404-15.

14. Chai L, Guo H, Li H, Wang S, Wang YL, Shi F, et al. Scutellarin and caffeic acid ester fraction, active components of Dengzhanxixin injection, upregulate neurotrophins synthesis and release in hypoxia/reoxygenation rat astrocytes. $J$ Ethnopharmacol 2013;150(1):100-7.

15. Tsai HD, Wu JS, Kao MH, Chen JJ, Sun GY, Ong WY, et al. Clinacanthus nutans Protects 
Cortical Neurons Against Hypoxia-Induced Toxicity by Downregulating HDAC1/6. Neuromolecular Med 2016;18(3):274-82.

16. Zhang Q, Qian Z, Pan L, Li H, Zhu H. Hypoxiainducible factor 1 mediates the anti-apoptosis of berberine in neurons during hypoxia/ischemia. Acta Physiol Hung 2012;99(3):311-23.

17. Jang JH, Son Y, Kang SS, Bae CS, Kim JC, Kim SH, et al. Neuropharmacological potential of gastrodia elata blume and its components. Evid Based Complement Alternat Med 2015; 2015:309261.

18. Jung, LS, He X, Song C, Ma CJ, Lee HY, Ahn J. Antioxidant, antibiofilm, and anticholinesterase activities of fermented Deodeok (Codonopsis lanceolata) extracts. Food Sci Biotechnol 2012; 21(5):1413-9.

19. Thiyagarajan M, Sharma SS. Neuroprotective effect of curcumin in middle cerebral artery occlusion induced focal cerebral ischemia in rats. Life sci 2004;74(8):969-85.

20. Wang YJ, Liu YH, Riao RX. Protective effect of tanshinone IIA on neurocyte apoptosis in rats with hypoxic ischemic brain damage and its mechanism. Chin Pharmaco Bull 2015:31(3) $: 443-4$.

21. Li Y, Wang L, Sun L, Chen J, Li HY, Wang C, et al. Effect of astragalus injection on the expression of VEGF and VEGF2 in rats with cerebral ischemia reperfusion injury. Chin Integrat Med Cardio-/Cerebrovascular Dis 2016;14(1):25-8.

22. Shin N, Kim HG, Shin HJ, Kim S, Kwon $\mathrm{HH}$, Baek H, et al. Uncoupled Endothelial Nitric Oxide Synthase Enhances p-Tau in Chronic Traumatic Encephalopathy Mouse Model. Antioxid Redox Signal 2019:30(13) :1601-20.

23. Green LC, Wagner DA, Glogowski J, Skipper
PL, Wishnok JS, Tannenbaum SR. Analysis of nitrate, nitrite, and [15N]nitrate in biological fluids. Anal Biochem 1982;126(1):131-8.

24. Kamal AA, Gomaa A, el Khafif M, Hammad AS. Plasma lipid peroxides among workers exposed to silica or asbestos dusts. Environ Res 1989; $49(2): 173-80$.

25. Ellman GL. Tissue sulfhydryl groups. Arch Biochem Biophys 1959:82(1):70-7.

26. Wheeler CR, Salzman JA, Elsayed NM, Omaye ST, Korte DW, Jr. Automated assays for superoxide dismutase, catalase, glutathione peroxidase, and glutathione reductase activity. Anal Biochem 1990;184(2) :193-9.

27. Chhunchha B, Fatma N, Kubo E, Rai P, Singh SP, Singh DP. Curcumin abates hypoxia-induced oxidative stress based-ER stress-mediated cell death in mouse hippocampal cells (HT22) by controlling Prdx6 and NF-kappaB regulation. Am J Physiol Cell Physiol 2013;304(7):636-55.

28. O’Donnell MJ, Xavier D, Liu L, Zhang H, Chin SL, Rao-Melacini $P$, et al. Risk factors for ischaemic and intracerebral haemorrhagic stroke in 22 countries (the INTERSTROKE study): a case-control study. Lancet 2010;376(9735): 112-23.

29. von Sarnowski B, Putaala J, Grittner U, Gaertner B, Schminke U, Curtze S, et al. Lifestyle risk factors for ischemic stroke and transient ischemic attack in young adults in the Stroke in Young Fabry Patients study. Stroke 2013;44(1) :119-25.

30. Alturkustani M, Ang LC, Ramsay D. Pathology of toxic leucoencephalopathy in drug abuse supports hypoxic-ischemic pathophysiology/etiology. Neuropathology 2017;37(4) :321-8.

31. Galinsky R, Lear CA, Dean JM, Wassink G, Dhillon SK, Fraser M, et al. Complex interactions 
between hypoxia-ischemia and inflammation in preterm brain injury. Dev Med Child Neurol 2018;60(2) :126-33.

32. Koh HS, Chang CY, Jeon SB, Yoon HJ, Ahn YH, Kim HS, et al. The HIF-1/glial TIM-3 axis controls inflammation-associated brain damage under hypoxia. Nat Commun 2015;6:6340.

33. Skovira JW, Wu J, Matyas JJ, Kumar A, Hanscom M, Kabadi SV, et al. Cell cycle inhibition reduces inflammatory responses, neuronal loss, and cognitive deficits induced by hypobaria exposure following traumatic brain injury. $J$ Neuroinflammation 2016;13(1):299.

34. Liu Y, Eaton ED, Wills TE, McCann SK, Antonic A, Howells DW. Human Ischaemic Cascade Studies Using SH-SY5Y Cells: a Systematic Review and Meta-Analysis. Transl Stroke Res 2018:9(6):564-74.

35. Shi X, Yu W, Yang T, Liu W, Zhao Y, Sun $Y$, et al. Panax notoginseng saponins provide neuroprotection by regulating NgR1/RhoA/ROCK2 pathway expression, in vitro and in vivo. $J$ Ethnopharmacol 2016;190:301-12.

36. Wong SB, Hung WC, Min MY. The Role of Gastrodin on Hippocampal Neurons after N-MethylD-Aspartate Excitotoxicity and Experimental Temporal Lobe Seizures. Chin J Physiol 2016; 59(3) :156-64.

37. Braun S, Liebetrau W, Berning B, Behl C. Dexamethasone-enhanced sensitivity of mouse hippocampal HT22 cells for oxidative stress is associated with the suppression of nuclear factor-kappaB. Neurosci Lett 2000;295(3):101-4.

38. Floyd RA. Antioxidants, oxidative stress, and degenerative neurological disorders. Proc Soc
Exp Biol Med 1999:222(3) :236-45.

39. Herbert V, Shaw S, Jayatilleke E, Stopler-Kasdan T. Most free-radical injury is iron-related: it is promoted by iron, hemin, holoferritin and vitamin $\mathrm{C}$, and inhibited by desferoxamine and apoferritin. Stem Cells 1994;12(3):289-303.

40. Fricker M, Tolkovsky AM, Borutaite V, Coleman M, Brown GC. Neuronal Cell Death. Physiol Rev 2018:98(2):813-80.

41. Zhang J, An SJ, Fu JQ, Liu P, Shao TM, Li $\mathrm{M}$, et al. Mixed Aqueous Extract of Salvia Miltiorrhiza Reduces Blood Pressure through Inhibition of Vascular Remodelling and Oxidative Stress in Spontaneously Hypertensive Rats. Cell Physiol Biochem 2016;40(1-2):347-60.

42. Zhang YJ, Wu L, Zhang QL, Li J, Yin FX, Yuan Y. Pharmacokinetics of phenolic compounds of Danshen extract in rat blood and brain by microdialysis sampling. J Ethnopharmacol 2011; 136(1) :129-36.

43. Kim HG, Lee JS, Choi MK, Han JM, Son CG. Ethanolic extract of Astragali radix and Salviae radix prohibits oxidative brain injury by psycho-emotional stress in whisker removal rat model. PLoS One 2014;9(5):e98329.

44. Kim HG, Lee JS, Han JM, Lee JS, Choi MK, Son SW, et al. Myelophil attenuates brain oxidative damage by modulating the hypothalamus-pituitaryadrenal (HPA) axis in a chronic cold-stress mouse model. J Ethnopharmacol 2013;148(2):505-14.

45. Lee JS, Kim HG, Han JM, Lee JS, Son SW, Ahn YC, et al. Myelophil ameliorates brain oxidative stress in mice subjected to restraint stress. Prog Neuropsychopharmacol Biol Psychiatry 2012;39(2) :339-47. 